\title{
Pupil cycle time and early autonomic involvement in ocular leprosy
}

Cerrahpasa School of Medicine, University of Istanbul, Turkey Department of Ophthalmology M A Karaçorlu Z Sürel

Department of Dermatology

C Mat

Istanbul Leprosy Hospital and Research Centre, Bakirköy, Istanbul, Turkey M A Karaçorlu T Çakiner E Hanyaloğlu T Saylan C Mat

Correspondence to: Mr M A Karaçorlu, Unalan, Site 59, D Blok, D14, Çamlica Istanbul, Turkey.

Accepted for publication 19 July 1990

Murat A Karaçorlu, Zeki Sürel, Tülay Çakiner, Erdal Hanyaloğlu, Türkan Saylan, Cem Mat

\begin{abstract}
Ocular complications of leprosy patients often develop insidiously and with few if any symptoms. This study involves measurement of the pupil cycle time (PCT) to evaluate the autonomic nerve system of the iris to determine the presence of subclinical intraocular involvement. The study included 19 lepromatous (LL), 19 borderline lepromatous (BL), and five borderline tuberculoid (BT) leprosy patients and involved 83 eyes. The control group included 25 healthy volunteers, 10 patients with pulmonary tuberculosis and eight with Duhring disease. The PCT was measured in these groups. In all leprosy groups included in the study the PCT was higher than in the control groups. Moreover, the PCT of the leprosy patients without any intraocular involvement was higher than in the controls. These results show that in the ophthalmic examination of leprosy patients without any symptoms the fact that autonomic nerve system of the eye is affected by the leprosy can often be determined by measuring the PCT.
\end{abstract}

Leprosy is a chronic infectious disease primarily affecting the peripheral nervous system and secondarily involving the skin, the mucosa of the mouth and upper respiratory tract, the reticuloendothelial system, eyes, bones, and testes. ${ }^{12}$ It is caused by Mycobacterium leprae and has been estimated to affect 10 to 15 million people throughout the world. ${ }^{34}$ In endemic regions a high proportion of the population come into contact with the bacillus, though $95 \%$ of these have a normal immune response and therefore do not develop leprosy. Of the remaining 5\% some cannont mount any response to the bacteria and so develop lepromatous leprosy (LL). Others develop a hypersensitivity reaction similar to that found in tuberculosis, which is therefore called tuberculoid leprosy (TT). ${ }^{5}$ These are two polar forms of the disease, but a full classification of the disease, put forward by Ridley and Jopling, ${ }^{6}$ includes intermediate forms of leprosy with characteristics of both groups. These are borderline lepromatous leprosy (BL), midborderline leprosy (BB), and borderline tuberculoid leprosy (BT).

Most authors would agree that the eye is frequently involved in leprosy, but actual figures vary enormously, from $1 \%$ to $100 \%,{ }^{7}$ The reasons for these large differences relate either to patterns and features of the disease and its distribution or to the protocol of the studies carried out. ${ }^{7}$

Transmission to the eye is generally thought to be by blood borne infection during a period when organisms are free in the bloodstream, but this is not entirely certain. For instance, the mycobacteria may reach the eye from the skin of the lids, the meibomian glands, or even from the nose via the lacrimal drainage system. ${ }^{8}$

Mycobacterium leprae probably begin to multiply in the ciliary body, which is richly supplied with blood vessels. They then spread into neighbouring structures such as the iris and cornea by direct extension or along nerve fibres and blood vessels. The bacillus causes destruction of some of the nerve tissue in the ciliary body and iris along with iridocyclitis as a result of its antigenic effect. In the long term, neurotrophic iritis, acute and chronic lepromatous iridocyclitis, and the complications following them are the causes of the patients' becoming blind. ${ }^{8}$

It has generally been accepted that among leprosy patients intraocular involvement occurs often in cases of lepromatous leprosy, less often in borderline lepromatous leprosy, and never in tuberculoid leprosy. Most authors also agree that it is uncommon to see intraocular signs in the first four or five years of the disease. However, if patients with the multibacillary disease remain untreated, an estimated $50 \%$ will develop visible eye lesions by the end of the first decade. ${ }^{8}$

ffytche 9 stated that early involvement of the autonomic nerves in the lepromatous iris, with their eventual destruction, and the late effects of neuroparalysis, include the slow atrophy of the iris muscle and associated chronic low-grade inflammatory changes. He also stated that in the early stages of lepromatous leprosy identification of autonomic involvement could lead to therapy designed to prevent dilator atrophy, with its complication of persistent miosis.

Swift and Bauschard ${ }^{10}$ have reported 11 cases of autonomic denervation hypersensistivity among 20 leprosy patients. However, to our knowledge there have been no reports of any testing or measurement methods to quantify subclinical intraocular involvement.

The purpose of this communication is to introduce a method which might be used in diagnosis. A thin slit-lamp beam illuminating the pupil margin produces clearly visible pupil oscillations. These oscillations can be timed with a stopwatch, thus producing a measurement of the 'edge-light pupil cycle time'. The pupil cycle time is remarkably stable in various testing situations and is repeatable. When the optic nerve is normal, the pupil cycle time is dependent on the innervation and integrity of the iris muscle. This study involves measurement of pupil cycle time (PCT) to evaluate the autonomic nerve system of the iris to determine the presence of subclinical intraocular involvement. Besides the leprosy patients we measured the PCT of pulmonary tuberculosis patients taking isoniazid and rifampicin and patients with Duhring disease 
taking dapsone as control groups. We also measured the PCT of healthy volunteers.

\section{Patients and methods}

This study included 19 patients with lepromatous leprosy (LL), 19 with borderline lepromatous leprosy (BL), and five with borderline tuberculoid leprosy (BT) and involved 83 eyes. Three patients, two from the LL group and one from the BL group, each had one eye which was not included into the study (two were excised following trauma and one was phithisic as a result of globe perforation). The control group included 25 healthy volunteers, 10 patients with pulmonary tuberculosis taking isoniazid and rifampicin, and eight Duhring disease patients with dapsone. The test was explained and informed consent was obtained. No patient after meeting the entry criteria refused to volunteer.

The type of leprosy was diagnosed according to the Ridley-Jopling ${ }^{6}$ classification on clinical, microbiological and histological basis. All subjects had normal optic nerve function as determined by direct ophthalmoscopic examination, absence of an afferent pupillary defect, and 6/6 best corrected acuity. Leprosy patients with active uveitis, posterior synechiae, or diffuse iris atrophy were not included in the study.

Corneal sensitivity was measured with a Cochet-Bonnet aesthesiometer. Sensitivity was considered to be affected or reduced if two quadrants of the cornea showed more than $10 \mathrm{~mm}$ of sensitivity reduction. Pupil. cycle time was measured according to Miller and Thompson. " The mean PCT of each pair of eyes was used in statistical analysis with the exception of three patients whose single eyes were included.

The average age of the LL and BL patients was close to the average age of the control group
39 (SD 11) and ranged from 22 to 61 years. The BT patients' average age was higher than the group as a whole, whereas the average age of the patients with Duhring disease and pulmonary tuberculosis was lower. When the duration of the diseases were investigated, the LL patients' disease duration was found to be on average 21 (SD 11) years, of BL patients 17 (SD 9) years, and of BT patients 14 (SD 9) years. Various characteristics of these groups were shown in (Table 1).

Treatment of $17(39.6 \%)$ of the leprosy patients ended at least three months prior to this study. Treatment of $26(60.4 \%)$ of the patients continued during this study. Subjects from the healthy control group did not use any topical or systemic medicine. Pulmonary tuberculosis and patients with Duhring disease had treatment during the study.

Statistical significance between population samples was determined by the two-tailed Student's $t$ test, multiple regression analysis, Pearson's correlation coefficient, and analysis of variance.

\section{Results}

Intraocular involvement was found in $16(37 \cdot 2 \%)$ patients, whereas $27(62 \cdot 8 \%)$ patients had none. Decreased corneal sensitivity was found in 15 (34.9\%) patients and normal sensitivity in the rest, that is, $28(65 \cdot 1 \%)$. Prominent corneal nerves were noted in $14(32 \cdot 6 \%)$ patients, corneal nerve beading in $10(23.3 \%)$ superficial punctate keratitis in $5(11.6 \%)$ and a superior quandrants subepithelial corneal scar in $6(14 \%)$. Chronic lepromatous iridocyclitis was found in $14(32 \cdot 6 \%)$ patients, whereas no symptoms (that is, keratic precipitates, iris atrophy, iris pearl, or sequelae of posterior synechiae) in the rest $29(67 \cdot 4 \%)$

Table 1 Group characteristics

\begin{tabular}{|c|c|c|c|c|c|c|}
\hline . & $\begin{array}{l}\text { No of } \\
\text { subjects }\end{array}$ & $\%$ & $\begin{array}{l}\text { Age }(y r): \\
\text { mean }(S D) \\
\text { [range] }\end{array}$ & $\begin{array}{l}\text { Duration of } \\
\text { diseases }(y r) \text { : } \\
\text { mean }(S D) \\
\text { [range] }\end{array}$ & $\begin{array}{l}\text { No of eyes } \\
\text { female }(\%)\end{array}$ & $\begin{array}{l}\text { No of eyes } \\
\text { male }(\%)\end{array}$ \\
\hline $\begin{array}{l}\text { Leprosy patients } \\
\text { Lepromatous leprosy (LL) }\end{array}$ & 19 & $44 \cdot 2$ & \multirow{4}{*}{$\begin{array}{l}37(13) \\
{[16-61]} \\
41(11) \\
{[25-74]} \\
48(9) \\
{[32-57]}\end{array}$} & \multirow{7}{*}{$\begin{array}{l}21(11) \\
{[4-45]} \\
17(9) \\
{[3-35]} \\
14(9) \\
{[1-25]}\end{array}$} & $6(31 \cdot 6)$ & $13(68 \cdot 4)$ \\
\hline Borderline lepromatous leprosy (BL) & 19 & $44 \cdot 2$ & & & $2(10 \cdot 5)$ & $17(89 \cdot 5)$ \\
\hline Borderline tuberculoid leprosy (BT) & 5 & $11 \cdot 6$ & & & $1(20 \cdot 0)$ & $4(80 \cdot 0)$ \\
\hline $\begin{array}{l}\text { Total } \\
\text { Control groups }\end{array}$ & 43 & 100 & & & & \\
\hline Healthy controls & 25 & & \multirow{3}{*}{$\begin{array}{l}39(11) \\
{[22-61]} \\
34(9) \\
{[19-51]} \\
30(6) \\
{[21-38]}\end{array}$} & & $13(52 \cdot 0)$ & $12(48 \cdot 0)$ \\
\hline Pulmonary tuberculosis & 10 & & & & $4(40 \cdot 0)$ & $6(60 \cdot 0)$ \\
\hline Duhring disease & 8 & & & & $3(37 \cdot 5)$ & $5(62 \cdot 5)$ \\
\hline
\end{tabular}

Table 2 Distribution of ocular findings in the different types of leprosy patients

\begin{tabular}{|c|c|c|c|c|c|c|c|}
\hline & \multicolumn{2}{|c|}{$\begin{array}{l}\text { Lepromatous } \\
\text { leprosy } \\
(n=19)\end{array}$} & \multicolumn{2}{|c|}{$\begin{array}{l}\text { Borderline } \\
\text { lepromatous } \\
\text { leprosy }(n=19)\end{array}$} & $\begin{array}{l}\text { Borderline } \\
\text { tuberculoid } \\
\text { leprosy }(n=5)\end{array}$ & \multicolumn{2}{|c|}{$\begin{array}{l}\text { Total } \\
(n=43)\end{array}$} \\
\hline & $N o$ & $\%$ & No & $\%$ & No \% & No & $\%$ \\
\hline $\begin{array}{l}\text { Prominent corneal nerves } \\
\text { Corneal nerve beading } \\
\text { Corneal hyperaesthesia } \\
\text { Superficial punctate keratitis } \\
\text { Superior quadrants subepithelial corneal scar } \\
\text { Iris atrophy (mild) } \\
\text { Iris pearl } \\
\text { Chronic lepromatous iridocyclitis }\end{array}$ & $\begin{array}{r}7 \\
6 \\
8 \\
3 \\
5 \\
3 \\
2 \\
10\end{array}$ & $\begin{array}{l}36 \cdot 8 \\
31 \cdot 6 \\
42 \cdot 1 \\
15 \cdot 8 \\
26 \cdot 3 \\
15 \cdot 8 \\
10 \cdot 5 \\
52 \cdot 6\end{array}$ & $\begin{array}{l}7 \\
4 \\
7 \\
2 \\
1 \\
3 \\
3 \\
1\end{array}$ & $\begin{array}{l}36 \cdot 8 \\
21 \cdot 0 \\
36 \cdot 8 \\
10 \cdot 5 \\
5 \cdot 3 \\
15 \cdot 8 \\
5 \cdot 3 \\
21 \cdot 0\end{array}$ & $\begin{array}{l}- \\
- \\
- \\
- \\
- \\
-\end{array}$ & $\begin{array}{r}14 \\
10 \\
15 \\
5 \\
6 \\
6 \\
3 \\
14\end{array}$ & $\begin{array}{r}32 \cdot 6 \\
23 \cdot 3 \\
34 \cdot 9 \\
11 \cdot 6 \\
14 \cdot 0 \\
14 \cdot 0 \\
7 \cdot 0 \\
32 \cdot 6\end{array}$ \\
\hline
\end{tabular}


Table 3 Types of leprosy and comparison of pupil cycle times

\begin{tabular}{|c|c|c|c|c|c|c|c|c|c|c|}
\hline & \multicolumn{3}{|c|}{ Lepromatous leprosy } & \multicolumn{3}{|c|}{ Borderline lepromatous leprosy } & \multicolumn{3}{|c|}{ Borderline tuberculoid leprosy } & \multirow{2}{*}{$\begin{array}{l}\text { Total } \\
\text { No of } \\
\text { patients } \\
(\%)\end{array}$} \\
\hline & $\begin{array}{l}\text { No of } \\
\text { patients } \\
(\%)\end{array}$ & $\begin{array}{l}\text { Mean cycle } \\
\text { time }(S D) \\
(m s)\end{array}$ & $\stackrel{p}{\text { Value }}$ & $\begin{array}{l}\text { No of } \\
\text { patients } \\
(\%)\end{array}$ & $\begin{array}{l}\text { Mean cycle } \\
\text { time }(S D) \\
\text { (ms) }\end{array}$ & $\stackrel{p}{\text { Value }}$ & $\begin{array}{l}\text { No of } \\
\text { patients } \\
(\%)\end{array}$ & $\begin{array}{l}\text { Mean cycle } \\
\text { time }(S D) \\
(m s)\end{array}$ & $\stackrel{p}{\text { Value }}$ & \\
\hline \multicolumn{11}{|l|}{ Multidrug therapy* } \\
\hline $\begin{array}{l}\text { Yes } \\
\text { No }\end{array}$ & $\begin{array}{r}13(68 \cdot 4) \\
6(31 \cdot 6)\end{array}$ & $\begin{array}{c}1012(248) \\
961(89)\end{array}$ & $\begin{array}{l}<0.001 \\
<0.001\end{array}$ & $\begin{array}{r}13(68 \cdot 4) \\
6(31 \cdot 6)\end{array}$ & $\begin{array}{r}936(159) \\
1016(119)\end{array}$ & $\begin{array}{l}<0.001 \\
<0.001\end{array}$ & $\begin{array}{l}0 \\
5(100)\end{array}$ & $\overline{9} 15(145)$ & $<0.001$ & $\begin{array}{l}26(60.4) \\
17(39.6)\end{array}$ \\
\hline \multicolumn{11}{|c|}{ Intraocular involvement } \\
\hline $\begin{array}{c}\text { Yes } \\
\text { No } \\
\text { Totals }\end{array}$ & $\begin{array}{r}9(47 \cdot 4) \\
10(52 \cdot 6) \\
19(44 \cdot 2)\end{array}$ & $\begin{array}{c}1086(282) \\
919(86) \\
1007(218)\end{array}$ & $\begin{array}{l}<0.001 \\
<0.001 \\
<0.001\end{array}$ & $\begin{array}{r}7(36 \cdot 8) \\
12(63 \cdot 2) \\
19(44 \cdot 2)\end{array}$ & $\begin{array}{r}1038(181) \\
924(132) \\
957(153)\end{array}$ & $\begin{array}{l}<0.001 \\
<0.001 \\
<0.001\end{array}$ & $\begin{array}{l}0 \\
5(100) \\
5(11 \cdot 6)\end{array}$ & $\begin{array}{l}\overline{915}(145) \\
915(145)\end{array}$ & $\begin{array}{l}<0.001 \\
<0.001\end{array}$ & $\begin{array}{l}16(37 \cdot 2) \\
27(62 \cdot 8) \\
43(100)\end{array}$ \\
\hline
\end{tabular}

$\star$ Dapsone + rifampicin + clofazimine or prothianamide.

patients. The distribution of ocular findings is shown in Table 2.

When pupil cycle time was studied, the healthy control group had an average PCT value of 820 (47) ms (mean and SD). Pulmonary tuberculosis and Duhring disease patients had average PCT values of 831 (37) ms and 828 (33) ms, respectively. LL patients had an average PCT value of 1007 (218) ms, BL patients had an average PCT value of 957 (153) $\mathrm{ms}$, and BT patients had an average PCT value of 915 (145) ms (Table 3 ).

The effect of age on PCT was tested in the healthy control group, the pulmonary tuberculosis patients, and the Duhring disease patients was not significant. Nor did age affect the PCT in LL, BL, and BT patients. The effects of the duration of the disease versus PCT was found to be insignificant for LL and BL groups, but for the BT group some dependency was evident $(r=0.667, p<0.02)$. The PCT of patients with pulmonary tuberculosis and Duhring disease was not significantly different from that of the healthy control group. Finally, the PCT of all leprosy groups versus healthy controls showed a significant difference $(p<0.001)$.

LL patients with intraocular involvement had an average PCT value of 1086 (282) $\mathrm{ms}$. BL patients with intraocular involvement had an average PCT value of 1038 (181) ms. The average PCT values of 919 (86) $\mathrm{ms}$ and 924 (132) ms were measured in the LL patients without any intraocular involvement and $\mathrm{BL}$ patients without any intraocular involvement, respectively. Although the last two PCT values were lower than the ones including patients with intraocular involvement, the difference between them and the PCT in the healthy control group was still statistically significant $(\mathrm{p}<0.001)$ (Table 3).

Also studied was the PCT difference between two eyes of all the subjects, It was 30 (13) ms when healthy control group subjects were studied, 40 (12) ms when it involved pulmonary tuberculosis group patients, and 36 (11) ms when Duhring disease patients were studied. These

Table 4 Comparison of the mean differences between cycle times of the fast and slow eye of a pair

\begin{tabular}{llll}
\hline & \multicolumn{2}{l}{$\begin{array}{l}\text { Mean difference between cycle times of the } \\
\text { fast and slow eye of } a \text { pair }(S D) \text { ms }\end{array}$} \\
\cline { 2 - 4 } & $\begin{array}{l}\text { Disease } \\
\text { groups }\end{array}$ & $\begin{array}{l}\text { Healthy } \\
\text { controls }(n=25)\end{array}$ & $p$ \\
\hline Lepromatous leprosy $\mathrm{n}=17$ & $94(63)$ & $30(13)$ & $<0.001$ \\
Borderline lepromatous leprosy $\mathrm{n}=18$ & $70(60)$ & $30(13)$ & $<0.001$ \\
Borderline tuberculoid leprosy $\mathrm{n}=5$ & $83(66)$ & $30(13)$ & $<0.001$ \\
Pulmonary tuberculosis $\mathrm{n}=10$ & $40(12)$ & $30(13)$ & $>0.05$ \\
Duhring disease $\mathrm{n}=8$ & $36(11)$ & $30(13)$ & $>0.05$ \\
\hline
\end{tabular}

numbers did not differ significantly $(p>0.05)$. However, when the PCT difference between two eyes was measured among LL, BL, and BT patients very different values were obtained in comparison with the control group, namely 94 (63) $\mathrm{ms}, 70(60) \mathrm{ms}$, and $83(66) \mathrm{ms}$, respectively. Comparison of these values with the PCT difference between the eyes in the controls shows a significant difference $(p<0.001)$ (Table 4).

Leprosy patients were divided into two groups, (1) continuing treatment, (2) no treatment (after treatment). In the first group the average PCT value of LL patients was 1012 (248) $\mathrm{ms}$ and of $\mathrm{BL}$ patients 936 (159) ms. In the second group the average PCT value of LL patients was 961 (89) ms, of BL patients 1016 (119) $\mathrm{ms}$, and of BT patients 915 (145) ms. When these values were compared with the PCT value of the control group, it was found that the difference was statistically significant $(p<0.001)$ and not due to the treatment (Table 3 ).

\section{Discussion}

In this study pupil cycle time of the healthy control group was determined to be 820 (SD 47) ms. Lepore and coworkers ${ }^{12}$ reported the PCT of a control group as 801.9 (SEM 8.9) ms. Miller and Thompson ${ }^{11}$ measured PCT of a control group as 822 (69) ms (mean and SD), and Campbell and Whiteside ${ }^{13}$ as $870(170) \mathrm{ms}$. In the present study the PCT difference between the eyes of the subjects from the control group was measured as 30 (13) ms whereas Miller and Thompson reported the PCT difference between the eyes as 30 (36) ms. ${ }^{11}$

In all three leprosy groups included in this study the PCT was higher than in the control group. Moreover, the PCT of the leprosy patients without any intraocular involvement was higher than in the control group. These results show that in the ophthalmic examination of leprosy patients without any symptoms such as keratic precipitates, posterior synechiae, sequelae of posterior synechiae, iris atrophy, iris pearl, etc, the fact that the autonomic nerve system of the eye suffers from the leprosy can often be determined by measuring the PCT.

An affected autonomic nerve system indicates the presence of Mycobacterium leprae in the eye. After the bacillus reaches the eye uveitic reactions will start, which may lead to blindness. Malaty and coworkers ${ }^{14}$ studied 70 nine-banded armadillos with leprosy and found that involvement of the ciliary body was $96 \%$, conjunctiva $68 \%$, iris $64 \%$, cornea $44 \%$, and choroidea $30 \%$. 
Leprosy causes various degrees of postganglionic autonomic denervation. Using this fact Swift and Bauchard ${ }^{10}$ tried to detect autonomic denervation hypersensitivity among leprosy patients. They showed the presence of denervation hypersensitivity using L-epinephrine $0.1 \%$ in 11 of the 20 leprosy patients. They reported that there was no obvious symptom for the 11 subjects with hypersensitivity, and 8 of the 9 subjects without any hypersensitivity showed symptoms of eye involvement. In other words, Swift and Bauchard found very few patients without any eye involvement as a result of leprosy. The fact that there was no denervation hypersensitivity among leprosy patients with eye involvement can be explained by difficulty of penetration of L-epinephrine through the intact cornea. The photographic determination of autonomic denervation hypersensitivity using L-epinephrine drops is a difficult method which requires large groups of subjects and extreme care in application.

The PCT therefore offers simple, fast, quantitiative measurements with a high degree of repeatability. And since the PCT can be measured at regular intervals it will probably give information about the autonomic nervous system and integrity of the iris along with a warning about the uveitic reactions. An increased
PCT distinguishes the patients with intraocular involvement from the rest of the group. In this way ophthalmologists can perform more frequent examinations of patients at risk and avert complications resulting from the insidious uveitic reactions.

1 Pfaltzgraff RE, Bryceson A. Clinical leprosy. In: Hastings RC ed. Leprosy. Churchill-Livingstone, Edinburgh, London, Melbourne, New York, 1985: 134-75.

2 Jopling WH. Handbook of leprosy. 2nd ed. London: Heinemann, 1978: 1-5, 66-74.

3 Noorden SK. The epidemiology of leprosy. In: Hastings RC ed. Leprosy. Churchill-Livinstone, Edinburgh, London, Melbourne, New York, 1985: 15-30.

4 Courtright P, Johnson GJ. Prevention of blindness in leprosy. London: International Centre for Eye Health, 1988: viii.

5 Binford CH, Meyers WM, Walsh GP. Leprosy. FAMA. 1982; 247: 2283-92.

6 Ridley DS, Jopling WH. Classification of leprosy according to immunity: a five-group system. Int $\mathcal{F}$ Lepr Other Mycobact

7 Courtright $P$. Defining the magnitude of ocular complications from leprosy: problems of methodology. Int $\mathcal{Y}$ Lepr Other Mycobact Dis 1988; 56: 566-73.

8 Brand MB. Care of the eye in Hansen's disease. 2nd ed. Carville LA: The Star, 1987: 3-14.

9 tfytche TJ. Role of iris changes as a cause of blindness in lepromatous leprosy. Br 7 Ophthalmol 1981; 65: 231-9.

10 Swift TR, Bauschard FD. Pupillary reactions in lepromatous leprosy. Int $\mathcal{F}$ Lepr Other Mycobact Dis 1972; 40: 142-8.

11 Miller SD, Thompson HS. Edge-light pupil cycle time. $\mathrm{Br} \mathcal{F}$ Ophthalmol 1978; 62: 495-500.

12 Lepore FE, Sanborn GE, Slevin JT. Pupillary dysfunction in myasthenia gravis. Ann Neurol 1979; 6: 29-33.

13 Campbell FW, Whiteside TCD. Induced pupillary oscillations. Brf Ophthalmol 1960; 34: 180-9.

14 Malaty R, Walsh GP, Meyers WM, Binford CH, Job CK Ocular leprosy in nine-banded armadillos. Invest Ophthalmo Vis Sci 1986; 27 (suppl 38). 